Article

\title{
Evaluation and Application of Satellite Precipitation Products in Studying the Summer Precipitation Variations over Taiwan
}

\author{
Wan-Ru Huang ${ }^{1, * \mathbb{D}}$, Pin-Yi Liu ${ }^{1}$, Ya-Hui Chang ${ }^{1}$ and Chian-Yi Liu ${ }^{2}$ \\ 1 Department of Earth Sciences, National Taiwan Normal University, Taipei 11677, Taiwan; \\ pinyiliu@ntnu.edu.tw (P.-Y.L.); yahuichang@ntnu.edu.tw (Y.-H.C.) \\ 2 Center for Space and Remote Sensing Research, National Central University, Taoyuan 32001, Taiwan; \\ cyliu@g.ncu.edu.tw \\ * Correspondence: wrhuang@ntnu.edu.tw
}

Received: 30 December 2019; Accepted: 20 January 2020; Published: 21 January 2020

\begin{abstract}
In March 2019, Integrated Multi-satellitE Retrievals for Global Precipitation Measurement (IMERG)-Final v6 (hereafter IMERG6) was released, with data concerning precipitation dating back to June 2000. The National Aeronautics and Space Administration (NASA) has suggested that researchers use IMERG6 to replace the frequently used Tropical Rainfall Measuring Mission (TRMM)-3B42 v7 (hereafter TRMM7), which is expected to cease operation in December 2019. This study aims to evaluate the performance of IMERG6 and TRMM7 in depicting the variations of summer (June, July, and August) precipitation over Taiwan during the period 2000-2017. Data used for the comparison also includes IMERG-Final v5 (hereafter IMERG5) and Global Satellite Mapping of Precipitation for Global Precipitation Measurement (GSMaP)-Gauge v7 (hereafter GSMaP7) during the summers of 2014-2017. Capabilities to apply the four satellite precipitation products (SPPs) in studying summer connective afternoon rainfall (CAR) events, which are the most frequently observed weather patterns in Taiwan, are also examined. Our analyses show that when using more than 400 local rain-gauge observations as a reference base for comparison, IMERG6 outperforms TRMM7 quantitatively and qualitatively, more accurately depicting the variations of the summer precipitation over Taiwan at multiple timescales (including mean status, daily, interannual, and diurnal). IMERG6 also performs better than TRMM7 in capturing the characteristics of CAR activities in Taiwan. These findings highlight that using IMERG6 to replace TRMM7 adds value in studying the spatial-temporal variations of summer precipitation over Taiwan. Furthermore, the analyses also indicated that IMERG6 outperforms IMERG5 and GSMaP7 in the examination of most of the features of summer precipitation over Taiwan during 2014-2017.
\end{abstract}

Keywords: assessment; satellite precipitation; Taiwan

\section{Introduction}

The Tropical Rainfall Measuring Mission (TRMM) was launched in November 1997 [1], and its most frequently used product, TRMM-3B42 v7 (hereafter TRMM7), is expected to cease in December 2019 (https://pmm.nasa.gov/data-access/downloads/trmm). As an extension and enhancements on the TRMM data, the Global Precipitation Measurement (GPM) Core Satellite was launched in February 2014 [2]. After that, the satellite precipitation products (hereafter SPPs) of the GPM mission, including Integrated Multi-satellitE Retrievals for GPM (IMERG) [3] and Global Satellite Mapping of Precipitation for GPM (GSMaP) [4], were provided by the National Aeronautics and Space Administration (NASA) and the Japan Aerospace Exploration Agency (JAXA), respectively. In March 2019, NASA released the IMERG-Final v6 (hereafter IMERG6), which includes TRMM-era 
data dating back to June 2000 and suggested that researchers use this for most research purposes (https://pmm.nasa.gov/data-access/downloads/trmm). However, the performance of these SPPs may depend heavily on location and season [5-12]. Thus, it is important to clarify which SPP (e.g., IMERG or GSMaP) is the most suitable product to replace TRMM7 for studies of precipitation changes over various regions and during various seasons [13-15]. A better understanding of the performance of SPPs [13-22] can benefit other studies where SPPs are required to examine issues that are related to precipitation (e.g., moisture budget, speed of the hydrological cycle, etc.).

Located in Asia, Taiwan $\left(119.9^{\circ} \mathrm{E}-122.1^{\circ} \mathrm{E}, 21.8^{\circ} \mathrm{N}-25.5^{\circ} \mathrm{N}\right)$ is an island that is known for its complex terrain (Figure 1b). In view of earlier literature, few studies have evaluated the performance of IMERG6 [15] or other SPPs over Taiwan [15,23-26]. Recently, Huang et al. [24] showed that IMERG-Final v5 (hereafter IMERG5), which is the earlier version of IMERG6, can qualitatively illustrate the multiple timescale variations in precipitation over Taiwan in a similar manner to the local rain-gauge observations made during the period March 2014-February 2017, but the amount of the estimation is lower than that seen in the gauge observations. However, Huang et al. [24] did not compare IMERG5 with the other SPPs used to investigate the precipitation around Taiwan. In addition, it should be noted that a major change was made to the morphing scheme used in IMERG5 and IMERG6 [3]. In versions of IMERG up to and including v5, the vectors used to describe cloud motion were computed from geosynchronous infrared brightness temperatures. In contrast, the morphing algorithm used in IMERG6 is modified to derive cloud motion vectors from variables in the Modern-Era Retrospective Analysis for Research and Applications Version 2 (MERRA-2) reanalysis [27]. Tan and Huffman [28] examined the global precipitation for August 2017 to October 2017 from IMERG5 and IMERG6, and noticed that IMERG6 outperforms IMERG5. However, the possibility that IMERG6 outperforms IMERG5 or any other SPPs with regards to precipitation over Taiwan has not been examined by Tan and Huffman [28].

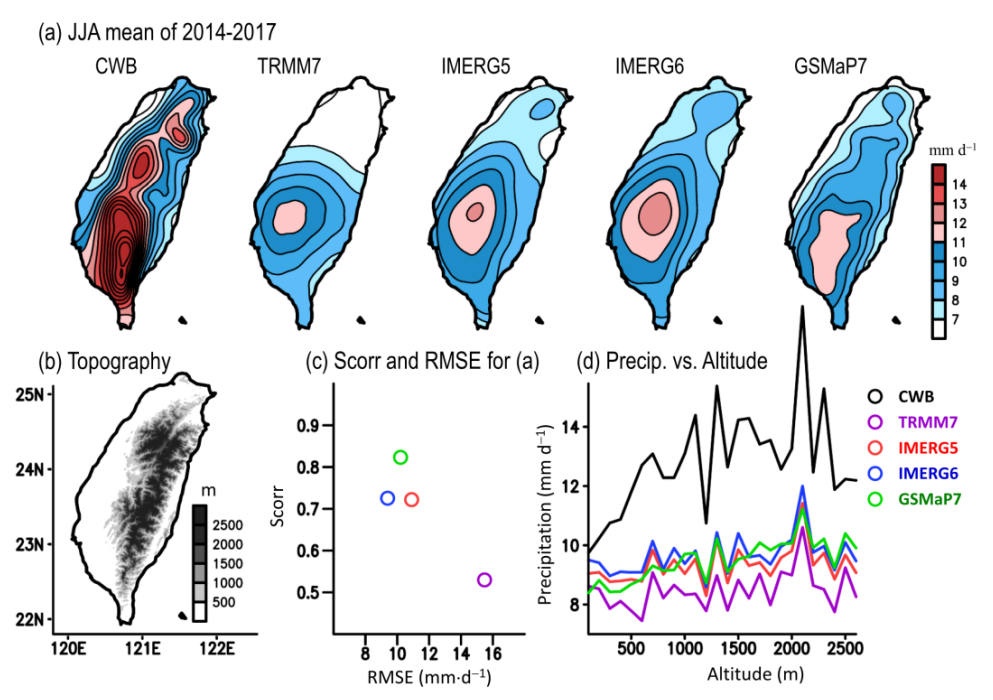

Figure 1. (a) Spatial distribution of summer mean precipitation over Taiwan, averaged during the summers (June, July, and August; JJA) of 2014-2017; from left to right is estimations made using Central Weather Bureau (CWB) data, Tropical Rainfall Measuring Mission-3B42 v7 (TRMM7), Integrated Multi-satellitE Retrievals for Global Precipitation Measurement-Final v5 (IMERG5) and v6 (IMERG6), and Global Satellite Mapping of Precipitation for Global Precipitation Measurement-Gauge v7 (GSMaP7). (b) The geographic location and topography of Taiwan. (c) The spatial correlation (Scorr) and the root mean square error (RMSE) for the comparison between the satellite precipitation products (SPPs) and the CWB data in (a). Here, the sample size is 392 grid points for the land areas in (a). (d) The estimations of the precipitation in (a), averaged by area at different altitudes. The color legends of $(\mathbf{c}, \mathbf{d})$ are given in the right panel of $(\mathbf{d})$. 
The GSMaP project, which was sponsored by Japan Science and Technology Agency during 2002-2007 and extended by JAXA, aims to develop microwave radiometer algorithms for producing high resolution global precipitation maps [29]. After the GPM mission was launched, a new algorithm was developed for the GSMaP project which included the GPM satellite data, producing GSMaP-Gauge data from March 2014 [4]. Recently, Derin et al. [15] pointed out that GSMaP-Gauge v7 (hereafter GSMaP7) and IMERG5 performed better than IMERG6 in depicting the precipitation formation over multiple complex terrain regions, including western Taiwan, during the period 2014-2015. However, only 34 gauges in western Taiwan and only two years of data from 2014-2015 were used by Derin et al. [15] as the reference base for comparison. It should be noted that there are more than 400 rain gauges across the entirety of Taiwan [24] that can be used for a more detailed comparison of SPPs starting from 2000. As the performance of SPPs might be location dependent and timing dependent [24], it is important to examine the performance of SPPs over Taiwan using higher density of rain gauges and longer time periods.

The main objective of this study was to evaluate the performance of multiple SPPs (including TRMM7, IMERG5, IMERG6, and GSMaP7) in depicting the spatial-temporal variations of summer (June, July, and August; JJA) precipitation over whole Taiwan, using more than 400 local rain gauges as the reference base for comparison. The selection of GPM SPPs followed Derin et al. [15]. However, in contrast to Derin et al. [15], who only performed the evaluation at daily and annual timescales, we perform the evaluation of summer precipitation at mean status, daily, interannual and diurnal timescales. In addition, we examine the capabilities to apply SPPs in studying the activities of summer connective afternoon rainfall (CAR) event (Figure 7, explained later), which is the most frequently observed weather pattern in Taiwan [30]. The analysis mainly focuses on the time periods that overlap in all data investigated, that is, the summers of 2014-2017 (Table 1), with an additional comparison between TRMM7 and IMERG6 for the summers of 2000-2017.

Table 1. Information about the satellite precipitation products (SPPs) used in this study.

\begin{tabular}{ccccc}
\hline & TRMM7 & IMERG5 & IMERG6 & GSMaP7 \\
\hline Spatial Resolution & $0.25^{\circ} \times 0.25^{\circ}$ & $0.1^{\circ} \times 0.1^{\circ}$ & $0.1^{\circ} \times 0.1^{\circ}$ & $0.1^{\circ} \times 0.1^{\circ}$ \\
Temporal Resolution & $3 \mathrm{Hour}$ & Half Hour & Half Hour & Hour \\
Coverage & $50^{\circ} \mathrm{S}-50^{\circ} \mathrm{N}$ & $60^{\circ} \mathrm{S}-60^{\circ} \mathrm{N}$ & $60^{\circ} \mathrm{S}-60^{\circ} \mathrm{N}$ & $60^{\circ} \mathrm{S}-60^{\circ} \mathrm{N}$ \\
Period & $1998 / 1-2019 / 10$ & $2014 / 3-2018 / 6$ & $2000 / 6-$ present & $2014 / 3-$ present \\
\hline
\end{tabular}

The remainder of this manuscript is arranged as follows. Information about the data and the statistical methodology are introduced in Section 2. Section 3 documents the evaluation and application of SPPs in studying the multiple timescale variations of summer precipitation over Taiwan. Discussions are provided in Section 4. A summary is given in Section 5 .

\section{Data and Methods}

\subsection{Data}

Following Huang et al. [24], the gridded hourly precipitation data produced from 436 rain-gauge observations provided by the Central Weather Bureau (hereafter CWB data) in Taiwan was used as the reference base for comparison. The Cressman scheme [31] was used to generate the gridded CWB data, following the procedures described by Hong and Cao [32].

Table 1 documents the basic information about SPPs used in this study. To compare with hourly CWB data, the 3-hourly TRMM7 were linearly interoperated into the hourly precipitation with a spatial resolution of $0.1^{\circ} \times 0.1^{\circ}$. Also, the two half-hourly IMERG estimations (unit: $\mathrm{mm} \cdot \mathrm{h}^{-1}$ ) were averaged to obtain hourly data [24]. All the hourly data were then converted into the local timescale in Taiwan, that is, universal time (UTC) +8 hours. 
The algorithms used by the four SPPs are briefly summarized below. According to Huffman et al. [1], four stages are implemented for the production of TRMM7: (1) precipitation estimates from the microwave sensor are calibrated and combined; (2) the infrared precipitation estimates are produced to extend the spatial coverage that the microwave observations do not cover; (3) the microwave and infrared precipitation estimates are combined; and (4) the monthly Global Precipitation Climatology Center (GPCC) gauge analysis product is used to climatologically adjust TRMM7 [1,5]. No gauge adjustment is required over the oceans. The TRMM7 data can be obtained from https: //pmm.nasa.gov/data-access/downloads/trmm.

According to Huffman et al. [33], the precipitation estimates of IMERG5 are produced using the following steps: (1) the individual satellite sensor data are gridded and calibrated to the combined microwave-radar estimates; (2) the precipitation estimates are propagated forwards and backwards in time using cloud motion vectors derived from infrared data; (3) the propagated precipitation estimates, along with the infrared estimates, are merged based on Kalman weighting factors; and (4) a bias correction is conducted using the monthly GPCC gauge analysis product. Unlike IMERG5, the cloud motion vectors of IMERG6 are derived from MERRA-2 variables [3]. The data of IMERG5 and IMERG6 are available at https://pmm.nasa.gov/data-access/downloads/gpm.

According to Mega et al. [4], several steps are followed for the production of GSMaP7: (1) a simplified and near real-time version of precipitation estimation is generated using fewer passive microwave input streams and a forward-only cloud advection scheme [34]; (2) an improved version of precipitation estimation is generated by applying the Kalman filter to assimilate and refine the visible/infrared-based precipitation rates [29]; (3) both forwards and backwards morphing is applied on the improved version of precipitation estimation to the area observed by the passive microwave radiometer to be affected by precipitation; and (4) a bias correction is conducted using the CPC unified gauge-based analysis of daily precipitation. The GSMaP7 data can be downloaded from https://sharaku.eorc.jaxa.jp/GSMaP/.

\subsection{Statistical Methods Applied for Comparison}

In this study, the root mean square error (RMSE) for the comparison between the SPPs and the CWB data is calculated based on Equation (1):

$$
\operatorname{RMSE}=\sqrt{\sum(\mathrm{SPPs}-\mathrm{CWB} \text { data })^{2} /(N-1)},
$$

where $N$ is the sample size [35]. The temporal correlation (Tcorr) [35] and the spatial correlation (Scorr) [35] between the SPPs and the CWB data are also calculated to evaluate the performance of SPPs.

Additionally, following the procedures in earlier literature [36-39], the frequently used threat score (TS) and bias score (BS) are adopted for quantitative evaluation of the precipitation estimations in Taiwan. The values of TS and BS are calculated based on Equations (2) and (3), respectively [36]:

$$
\begin{gathered}
\mathrm{TS}=\mathrm{H} /(\mathrm{O}+\mathrm{F}-\mathrm{H}), \\
\mathrm{BS}=\mathrm{F} / \mathrm{O},
\end{gathered}
$$

where $\mathrm{O}$ is the area (i.e., number of grid points) of precipitation depicted by the CWB data that exceeds a given precipitation threshold, $\mathrm{F}$ is the area of precipitation depicted by the selected SPP that exceeds the given precipitation threshold, and $\mathrm{H}$ is the intersection of $\mathrm{O}$ and $\mathrm{F}$ over a period of accumulation. The worst and best possible values for TS are 0 and 1 , respectively. BS can be described by any value from 0 to infinity. As stated in Levizzani et al. [40], BS gives the ratio of the estimated rain area (frequency) to the observed rain area (frequency), regardless of how well the rain patterns correspond with each other. TS measures the fraction of all events estimated and/or observed that were correctly diagnosed. For other details of TS and BS, please refer to Levizzani [40]. 
Moreover, to clarify the spatial-temporal characteristics of diurnal precipitation over Taiwan, we applied the widely used empirical orthogonal function (EOF) analysis [41] on the variation of diurnal precipitation. For more details of EOF analysis, please refer to Hannachi et al. [41].

\section{Results}

\subsection{Mean Status}

Figure 1a shows the spatial distribution of precipitation over Taiwan, averaged from summers of 2014-2017. From the CWB data, it is noted that larger precipitation is observed in southwest Taiwan than in the other sub-regions. This is due to the interaction between the prevailing southwesterly summer monsoonal flow (not shown) and the local topography (Figure 1b), which can lead to more precipitation occurring on the windward side of the mountains (i.e., southwest Taiwan) [30]. Visually, all four of the SPPs can qualitatively depict the feature with more significant precipitation over southwest Taiwan. However, GSMap7 seems better than the others in illustrating the location of maximum precipitation. This might due to the inclusion of an orographic effect for additional upward motion and moisture flux convergence in the GSMaP algorithm [29,42].

Also worth noting in Figure 1a, all four of the SPPs tend to underestimate the amount of summer mean precipitation over most areas of Taiwan. This might be because that satellite methods underestimate heavy precipitation associated with shallow orographic precipitation systems [42]. Despite the weakness in validating the magnitude of precipitation, a further comparison between the values of precipitation area-averaged over Taiwan indicates that IMERG6 $\left(\sim 8.9 \mathrm{~mm} \cdot \mathrm{d}^{-1}\right)$, relative to the other SPPs (TRMM7 8.0, IMERG5 8.5, and GSMaP7 $8.6 \mathrm{~mm} \cdot \mathrm{d}^{-1}$ ), is closer to the CWB data $\left(\sim 11.0 \mathrm{~mm} \cdot \mathrm{d}^{-1}\right)$.

Based on Figure 1a, the Scorr and the RMSE are then calculated for the comparison between the SPPs and the CWB data. As seen in Figure 1c, TRMM7 has the largest RMSE and the smallest Scorr. Compared to the performance of TRMM7 (i.e., Scorr $=0.53$, RMSE $=15.5 \mathrm{~mm} \cdot \mathrm{d}^{-1}$ ), the Scorr of IMERG6 $(\sim 0.73)$ is increased by approximately $37.7 \%[=(0.73-0.53) / 0.53 \times 100 \%]$ and the RMSE of IMERG6 $\left(\sim 9.4 \mathrm{~mm} \cdot \mathrm{d}^{-1}\right)$ is reduced by approximately $39.4 \%[=(15.5-9.4) / 15.5 \times 100 \%]$. This suggests that using IMERG6 to replace TRMM7 can increase the performance by approximately $35 \% \sim 40 \%$ in depicting the spatial distribution of summer mean precipitation over Taiwan.

In addition to IMERG6, IMERG5 (i.e., Scorr $=0.72$, RMSE $=10.9 \mathrm{~mm} \cdot \mathrm{d}^{-1}$ ) and GSMaP7 (i.e., Scorr $=0.82$, RMSE $=10.2 \mathrm{~mm} \cdot \mathrm{d}^{-1}$ ) also outperform TRMM7 in illustrating the spatial distribution of summer mean precipitation over Taiwan (Figure 1c). Part of the reason for this might be that the original spatial resolution of IMERG5, IMERG6, and GSMaP7 $\left(0.1^{\circ} \times 0.1^{\circ}\right)$ is higher than that of TRMM7 $\left(0.25^{\circ} \times 0.25^{\circ}\right)$. Therefore, although TRMM7 has been re-gridded into the same spatial resolution $\left(0.1^{\circ} \times 0.1^{\circ}\right)$ for the comparison (see Section 2), the performance of TRMM7 is still worse than the other higher resolution SPPs for depicting the precipitation that occurs over complex terrain.

To reveal whether the above suggestion is dependent on the altitude, we further compared the performance of SPPs at different altitudes. Worth noting in Figure 1d, there is an obvious increase in the difference between the SPPs and the CWB data, as the altitude increases. Among the four SPPs, the performance of IMERG6 (GSMaP7) is closer to the CWB data at most altitudes below $1000 \mathrm{~m}$ (higher than $1500 \mathrm{~m}$ ), while TRMM7 has the largest bias over most altitudes. These features indicate again that the new GPM SPPs (including IMERG5, IMERG6, and GSMaP7) outperform TRMM7 in depicting the distribution of summer mean precipitation over Taiwan; this finding is not dependent on the altitude.

\subsection{Day-to-Day and Interannual Variation}

Figure 2a shows the time series of the 5-day running mean for the precipitation area-averaged over Taiwan during the summers of 2014-2017. Using the time series in Figure 2a, two statistical scores, Tcorr and RMSE, between the CWB data and the SPPs, were then calculated for providing evaluation evidence. As seen in Figure 2b, all SPPs have similar values of Tcorr ( 0.9), but the lowest RMSE is 
observed in IMERG6 and the highest RMSE is observed in TRMM7. Overall, the RMSE of IMERG6 $\left(\sim 7.6 \mathrm{~mm} \cdot \mathrm{d}^{-1}\right)$ is approximately $12.6 \%$ lower $[=(8.7-7.6) / 8.7 \times 100 \%]$ than the RMSE of TRMM7 $\left(\sim 8.7 \mathrm{~mm} \cdot \mathrm{d}^{-1}\right)$.

(a) 5-day running averaged Precip. over Taiwan

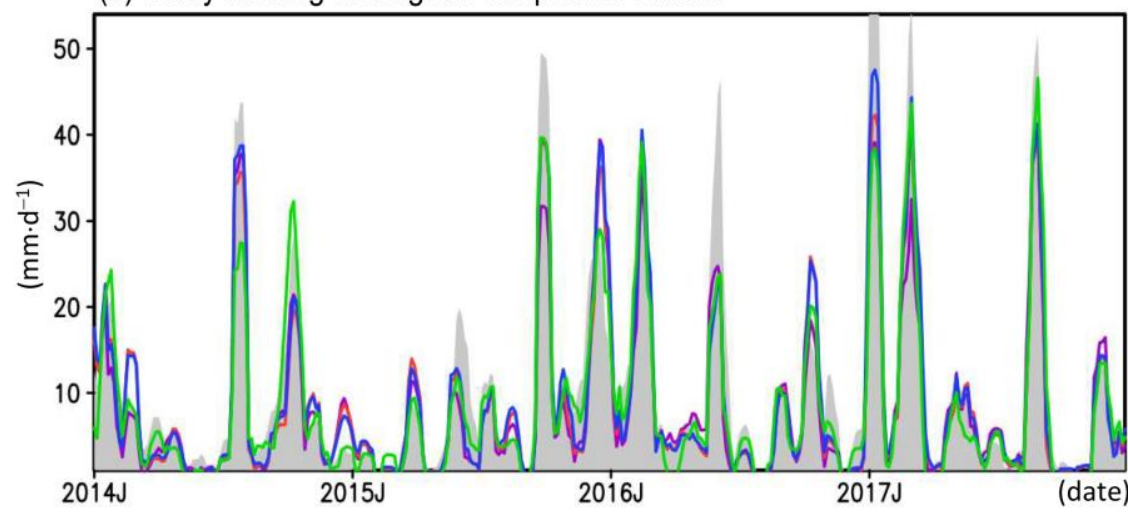

(c) Tcorr (satellite products vs. CWB data); 2014-2017 JJAs
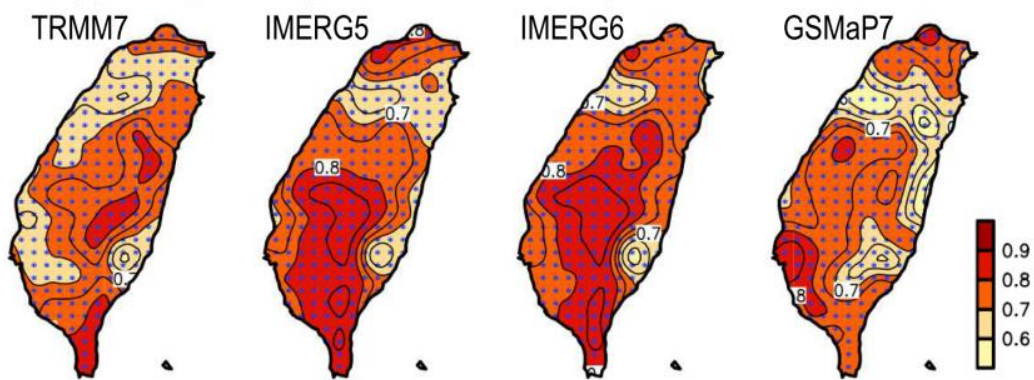

(d) RMSE (satellite products vs. CWB data); 2014-2017 JJAs
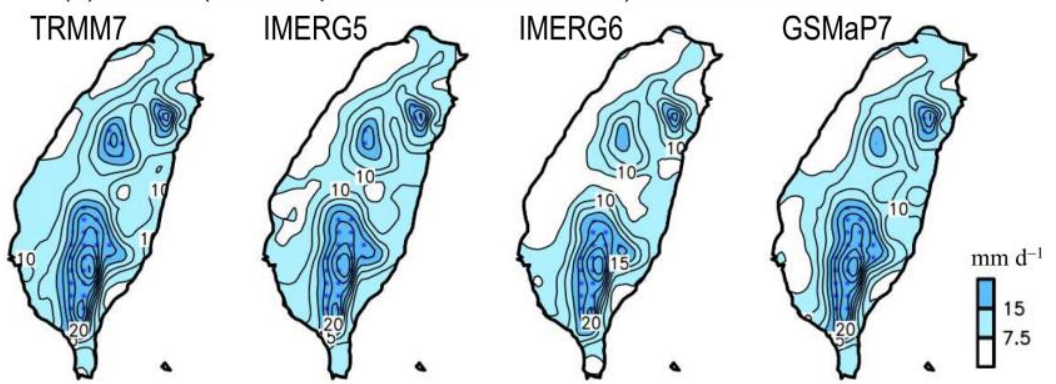

Figure 2. (a) Time series of 5-day running averaged precipitation over Taiwan, during the summers of 2014-2017, extracted from the CWB data and the four SPPs. The color symbols are described in (b).

(b) Tcorr (i.e., temporal correlation) and RMSE between the time series of CWB data and SPPs in (a).

(c) Grid-to-grid Tcorr between the time series of CWB data and SPPs. (d) Grid-to-grid RMSE between the time series of CWB data and SPPs. Here, the sample size for calculating Tcorr and RMSE is 368 days from summers of 2014-2017. In (c,d), the values pass the $99 \%$ significant test are marked by dots.

Additionally, as noted from Figure 2c, which shows the spatial distribution of grid-to-grid Tcorr for the comparison between the SPPs and the CWB data, IMERG6 has more areas with larger values of Tcorr (e.g., >0.8). Moreover, even though the related spatial distributions of grid-to-grid RMSE in Figure $2 \mathrm{~d}$ do not show too much difference among the performance of the four SPPs, IMERG6 is still the one having more areas with smaller values of RMSE (e.g., $<7.5 \mathrm{~mm} \cdot \mathrm{d}^{-1}$ ). These features suggest that the performance of IMERG6 is overall better than the other SPPs in depicting the day-to-day variations of precipitation over Taiwan.

Recall, Derin et al. [15] indicated that IMERG6 performed worse than GSMaP7 and IMERG5 in capturing the daily precipitation formation over western Taiwan during 2014-2015. Consistent 
with Derin et al. [15], one can note from Figure 2c that GSMaP7 and IMERG5 did perform better than IMERG6 in some coastal regions of southwest Taiwan, even though the time periods used for the comparison are different in Figure 2c and Derin et al. [15]. However, in contrast to Derin et al. [15], we would like to call attention that when focused on the daily precipitation formation over whole Taiwan during the summers of 2014-2017, the performance of IMERG6 is overall better than GSMaP7 and IMERG5.

Next, statistical evidence is provided for evaluating the capabilities of IMERG6 and TRMM7 to depict the variations of daily precipitation events during the summers of 2000-2017. Figure 3a shows the distribution of the occurrence frequency of precipitation events at various ranges of intensity (units: $\mathrm{mm} \cdot \mathrm{d}^{-1}$ ). From Figure 3a, we note that both TRMM7 and IMERG6 tend to underestimate the occurrence frequency of precipitation events at most ranges of intensity. Despite that, the performance of IMERG6 is overall better (i.e., more close to the CWB data) than TRMM7, in particularly for capturing the occurrence frequency of light precipitation events (see right top panel of Figure 3a).

(a) Frequency and intensity of events; 2000-2017 JJAs

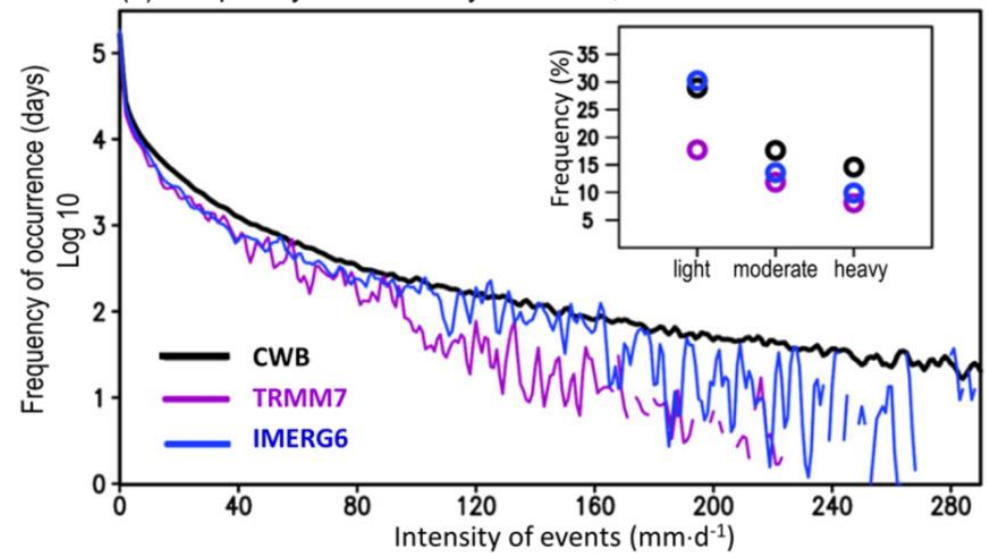

(b) TS score
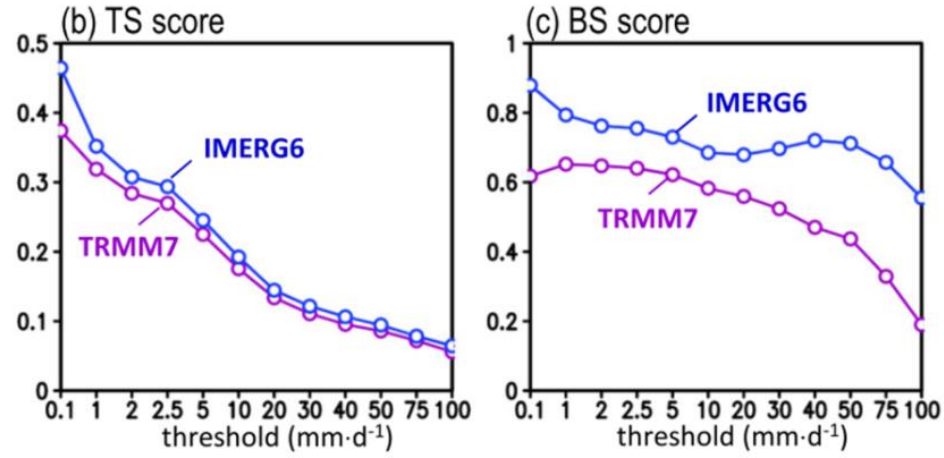

Figure 3. (a) Histograms of the frequency of occurrence as a function of daily precipitation intensity (bin size is $1 \mathrm{~mm} \cdot \mathrm{d}^{-1}$ ) in Taiwan during the summers of 2000-2017. Inset plots represent the frequency (in \%) of light $\left(0.1-5 \mathrm{~mm} \cdot \mathrm{d}^{-1}\right)$, moderate $\left(5-20 \mathrm{~mm} \cdot \mathrm{d}^{-1}\right)$, and heavy precipitation $\left(>20 \mathrm{~mm} \cdot \mathrm{d}^{-1}\right)$ events. The method used for generating (a) follows Sun et al. [43]. (b) and (c) is the value of TS and BS (explained in Section 2), respectively, for the comparison between CWB data and two SPPs (IMERG6 and TRMM7) during the summers of 2000-2017. The sample size used here is 92 (days per JJA) $\times 18(\mathrm{JJAs}) \times 392$ (grid points per day) $=649152$ grid points.

Moreover, two other statistical scores, TS (i.e., threat score) and BS (i.e., bias score), are calculated for representing the skill of SPPs in quantitative precipitation estimations. It can be noted in Figure $3 \mathrm{~b}$ that the value of TS in IMERG6 is higher than in TRMM7 over all ranges of precipitation threshold. As higher TS values indicate better performance [36], Figure 3b again suggests that IMERG6 outperforms TRMM7. On the other hand, both IMERG6 and TRMM7 have values of BS $<1$ over all ranges of precipitation threshold. This implies that precipitation events in both IMERG6 and TRMM7 occurred 
less often than that in the CWB data [36]. However, relative to TRMM7, IMERG6 still has a BS value closer to the ideal value of 1 .

Figure 4 a shows the interannual variation of summer precipitation, area-averaged over Taiwan, estimated by the CWB data and the SPPs. Consistent with Figure 3a, the variations of IMERG6 (TRMM7) is more (less) close to the CWB data during the summers of 2000-2017. The spatial distribution of grid-to-grid Tcorr (RMSE) between the SPPs and the CWB data are further conducted in Figure $4 \mathrm{~b}$ (Figure 4c) for evaluating the performance of TRMM7 and IMERG6. It is noted that IMERG6 (TRMM7) has more (less) areas with Tcorr $>0.8$ and RMSE $<5 \mathrm{~mm} \cdot \mathrm{d}^{-1}$, suggesting again that IMERG6 outperforms TRMM7.

(a) Interannual variation of JJA Prec. over Taiwan

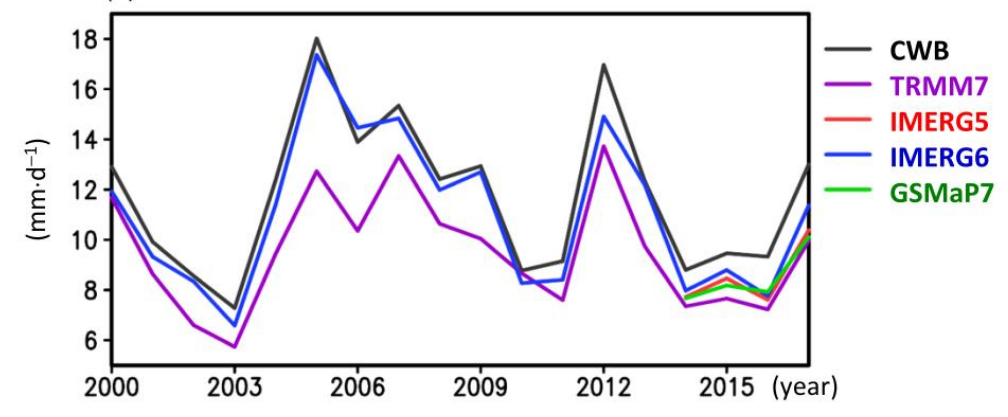

(b) Tcorr (satellite products vs. CWB data)

(c) RMSE (satellite products vs. CWB data)
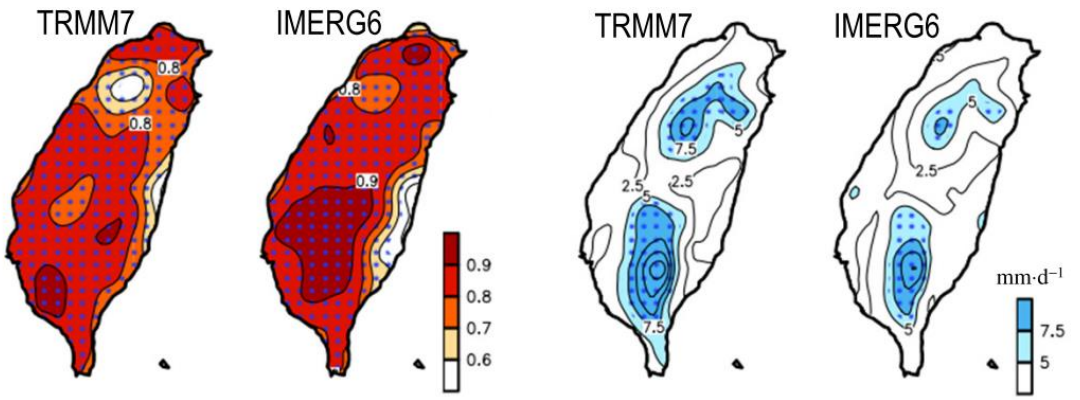

Figure 4. (a) Time series of the mean precipitation for the summers of 2000-2017, area-averaged over Taiwan, as estimated by the CWB data and SPPs. (b) and (c) is the related grid-to-grid Tcorr and RMSE, respectively, between the CWB data and the selected SPPs: TRMM7 and IMERG6. Here, the sample size for calculating Tcorr and RMSE is 18 JJAs. In (b,c), the values pass the $99 \%$ significant test are marked by dots.

Also, for the performance of IMERG5 and GSMaP7 in illustrating the interannual variation of summer precipitation over Taiwan, some information is given in Figure 4a. It was found that even when focused on the summers of 2014-2017, IMERG6 (TRMM7) is still more (less) close to the CWB data, as compared to the other SPPs.

\subsection{Diurnal Variation}

The summer precipitation over Taiwan also exhibits a clear diurnal feature in which the maximum precipitation generally occurs in the afternoon [24,30]. To illustrate this feature, we apply an EOF analysis on the variation of diurnal precipitation, averaged during the summers of 2014-2017. This analysis method is frequently adopted by earlier studies in examining the characteristics of diurnal variation of precipitation over East Asia [44-46]. Here, only the first mode of the EOF analysis is presented in Figure 5, and several features noted from Figure 5 are summarized below: 
1. The first EOF mode of the CWB data explains about $62.6 \%$ of the total variability of diurnal precipitation. Among the four SPPs, IMERG6 (GSMaP7) has the number of percentage more (less) close to the CWB data.

2. Spatially (Figure 5a), the first EOF mode of the CWB data shows two maximum centers: one in central-west Taiwan and the other in northern Taiwan. For the SPPs, all of them are able to show two maximum centers in Figure 5a. However, the locations of the maximum centers in GSMaP7 are apparently shifted to the west compared to the CWB data.

3. Temporally (Figure 5b), the first EOF mode of the CWB data shows the timing of diurnal precipitation maximum occurred between 15-18 h. For the SPPs, all of them are able to capture similar feature in Figure 5b, even though their amplitudes of diurnal variation are weaker than the CWB data. Among the four SPPs, GSMaP7 underestimates the most in the amplitude of diurnal variation of precipitation.

(a) Normalized spatial pattern of the first EOF mode of diurnal precipitation
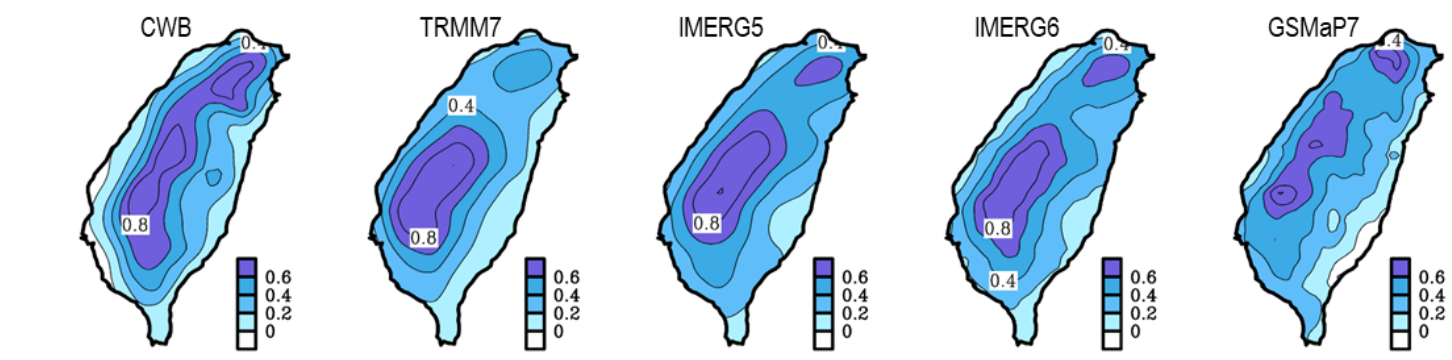

(b) Temporal pattern of the first EOF mode of diurnal precipitation
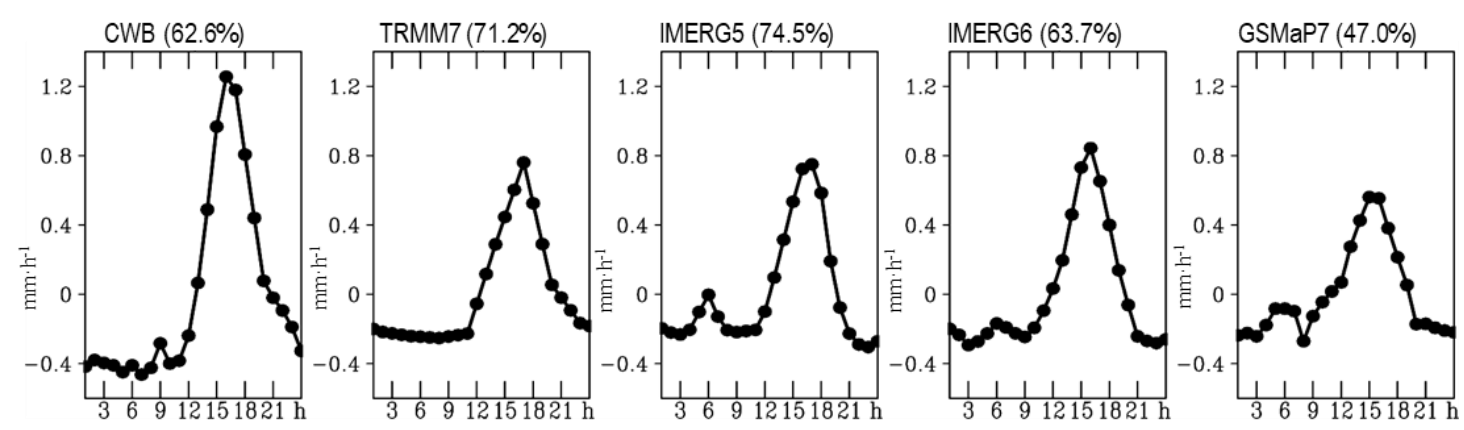

Figure 5. The first empirical orthogonal function (EOF) mode of diurnal precipitation, averaged during the summers of 2014-2017: (a) the normalized spatial patterns (i.e., eigen-vectors normalized to the maximum precipitation), and (b) the temporal patterns (i.e., eigen-coefficients). The percentages (\%) of the total variability in hourly precipitation explained by the first EOF mode are added in (b).

Based on Figure 5, it seems that GSMaP7 performs worse than the other SPPs in illustrating the diurnal variation of precipitation. Indeed, by calculating the Scorr (RMSE) between the SPPs and the CWB data from Figure 5a, we note from Table 2 that GSMaP7 has the lowest (highest) value of Scorr (RMSE), suggesting its spatial pattern is less similar to the CWB data. In addition, by calculating the Tcorr (RMSE) between the SPPs and the CWB data from Figure 5b, we note from Table 2 that GSMaP7 has the lowest (highest) value of Tcorr (RMSE), suggesting its temporal pattern is also less similar to the CWB data.

It is also apparent from Table 2 that IMERG6 has the smallest bias in capturing the spatial-temporal characteristics of the diurnal precipitation over Taiwan. Tan et al. [47] examined the performance of IMERG6 in capturing the diurnal cycle of precipitation over the southeastern United States also noted that IMERG6 tends to underestimate the diurnal amplitude, but is capable of depicting the phase of diurnal precipitation. However, why IMERG6 (GSMaP7) performs the best (worst) with regards to the diurnal precipitation over Taiwan is unclear and requires further study. 
Table 2. Statistical values for the comparison between the CWB data and SPPs shown in Figure 5. The unit of RMSE is $\mathrm{mm} \cdot \mathrm{d}^{-1}$. The lowest value of Scorr and Tcorr, as well as the highest value of RMSE, are marked by *. The sample size of spatial variation is 392 grid points. The sample size of temporal variation is 24 hours.

\begin{tabular}{ccccc}
\hline & TRMM7 & IMERG5 & IMERG6 & GSMaP7 \\
\hline Scorr for Figure 5a & 0.83 & 0.88 & 0.89 & $0.74^{*}$ \\
RMSE for Figure 5a & 0.17 & 0.16 & 0.14 & $0.20^{*}$ \\
Tcorr for Figure 5b & 0.92 & 0.94 & 0.94 & $0.85^{*}$ \\
RMSE for Figure 5b & 0.26 & 0.24 & 0.23 & $0.35^{*}$ \\
\hline
\end{tabular}

The performance of IMERG6 and TRMM7 in illustrating the variation of diurnal precipitation area-averaged over Taiwan during the summers of 2000-2017 was further evaluated based on Figure 6. The CWB data (Figure 6a) shows that all examined periods have maximum diurnal precipitation occurred between 15-18 h. By comparing Figure 6a with Figure 6b,c, we note that both TRMM7 and IMERG6 are able to show the temporal phase evolution similar to the CWB data, with the value of Scorr between Figures $6 \mathrm{a}$ and $6 \mathrm{~b}$ (Figure 6c) is about 0.91 (0.92). However, it is also apparent in Figure 6 that both TRMM7 and IMERG6 tend to underestimate the amplitude of diurnal precipitation for all examined time periods, but TRMM7 (IMERG6) is less (more) close to the CWB data. All above features revealed in Figure 6 are consistent with those suggested by Figure 5 and Table 2, suggesting again that IMERG6 is better than TRMM7 in depicting the variation of diurnal precipitation over Taiwan.

(a) CWB

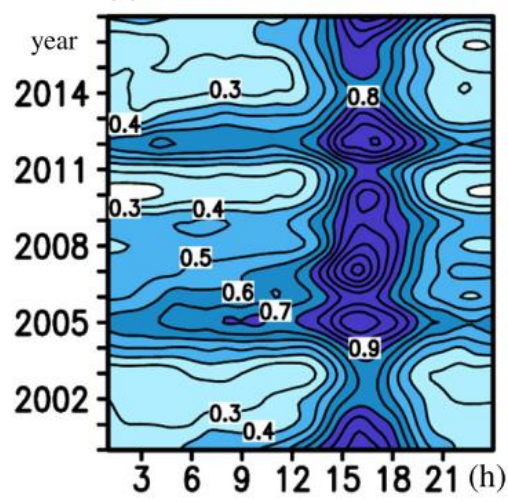

(b) TRMM7

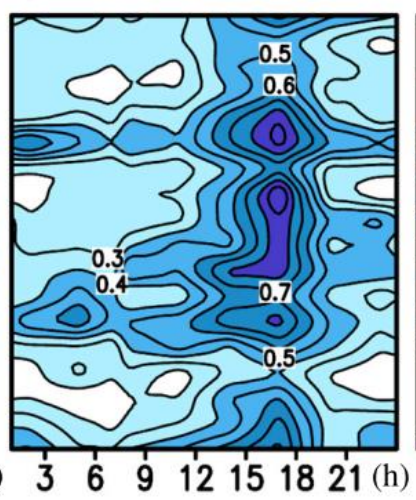

(c) IMERG6

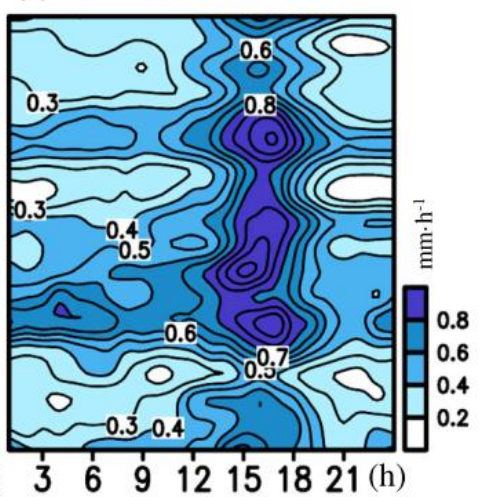

Figure 6. Temporal evolution of the hourly precipitation area-averaged over Taiwan extracted from the selected data for each specific summer during 2000-2017: (a) the CWB data, (b) TRMM7, and (c) IMERG6.

\subsection{Potential Applications}

Based on findings of Sections 3.1-3.3, we then infer that applying IMERG6 to the study of summer convective afternoon rainfall (CAR) events over Taiwan (e.g., Figure 7a), which generally includes a diurnal precipitation maximum in the afternoon after the local thermal heating maximum (e.g., Figure $7 b$ ), can obtain results more similar to those seen in the CWB data. This inference will be clarified by the examinations presented in this sub-section. Hereafter, the methods used for the identification of CAR events follow Huang et al. [30], and are briefly summarized as follows: (1) a rainy day is defined as a day with an accumulated precipitation of $\geq 0.1 \mathrm{~mm}$; (2) the accumulated precipitation of a rainy day during the time period $1200-2200 \mathrm{~h}$ is $>80 \%$ of the daily precipitation; (3) the accumulated precipitation of a rainy day during the time period $0100-1100 \mathrm{~h}$ is $<10 \%$ of the daily precipitation; and (4) days affected by other weather systems (e.g., typhoons and frontal systems) are excluded. 
(a) IR image (20 June 2016, 17 h)

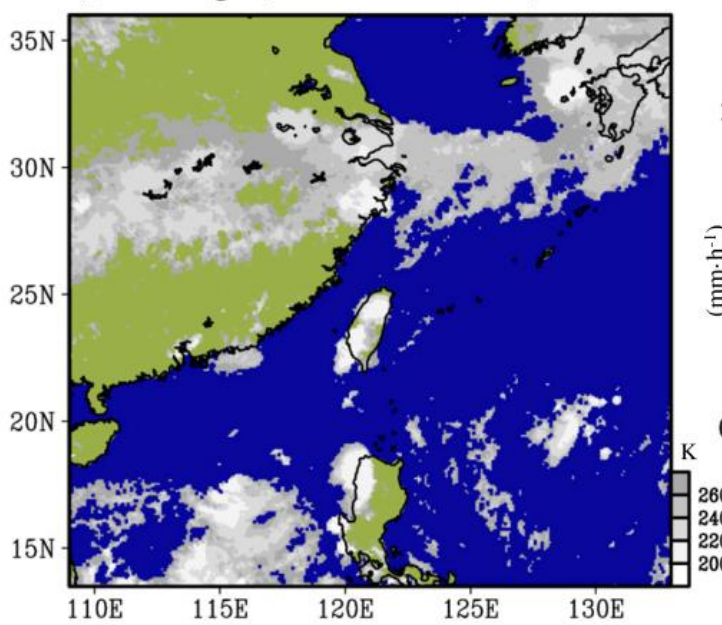

(b) Precipitation \& Ts in Taiwan

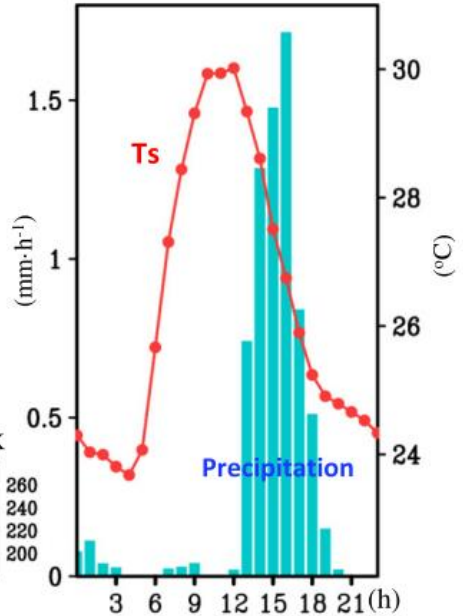

Figure 7. (a) Infrared cloud image, obtained from Gridded Satellite B1 Observations (https://www. ncdc.noaa.gov/gridsat/), for an example of convective afternoon rainfall (CAR) event that occurred on 20 June 2016, 17 h (local time) in Taiwan. (b) Time series of hourly precipitation (bars) and surface temperature (Ts, red line) averaged from local stations in Taiwan for the event shown in (a).

Figure 8 shows the spatial distribution for the contribution of CAR activities (including occurrence frequency and precipitation amount) to the total summer precipitation events, averaged over the summers of 2014-2017. In Figure 8a (Figure 8b), the CWB data shows that CAR events contribute more than $40 \%(30 \%)$ of the occurrence frequency (precipitation amount) of the total precipitation events in most areas of Taiwan. Furthermore, similar to Figure 5a, two maximum centers are revealed in the CAR activities observed by the CWB data. Despite the location difference, all SPPs are able to show two maximum centers in the CAR activities; however, GSMaP7 apparently underestimates the most in the contribution of CAR activities to the total precipitation events.
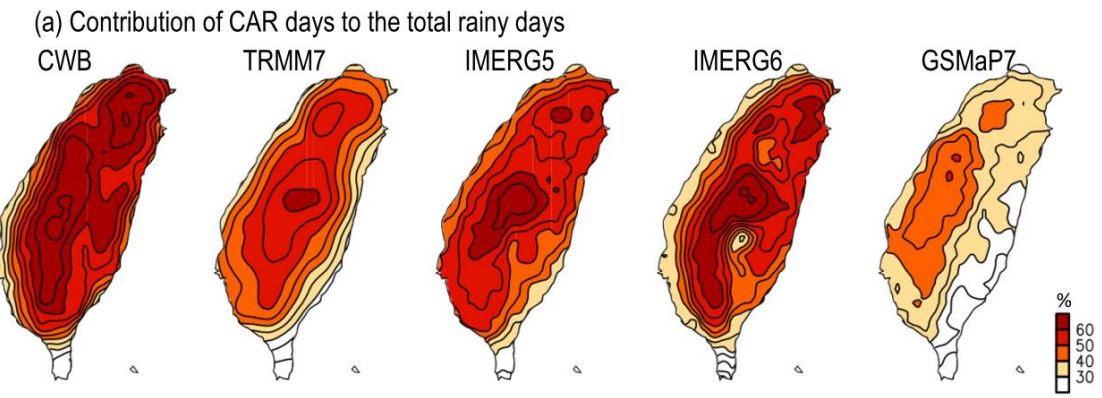

(b) Contribution of CAR precipitation amounts to the total precipitation amounts
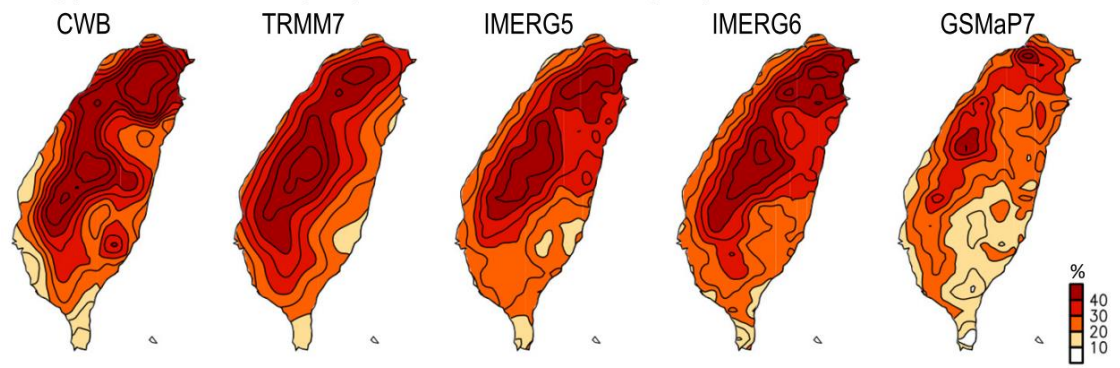

Figure 8. Contribution of CAR events to total precipitation events during the summers of 2014-2017: (a) frequency of occurrence, $(\mathbf{b})$ amount of precipitation. In $(\mathbf{a}, \mathbf{b})$, contribution $=\frac{\text { CAR events }}{\text { Total precipitation events }} \times 100 \%$. 
By comparing the CWB data with the four SPPs in Figure 8, two statistical scores (Scorr and RMSE) were calculated and documented in Table 3. It can be noted in Table 3 that IMERG6 (with the highest Scorr and the lowest RMSE) outperforms the other SPPs, while the greatest bias is seen in GSMaP7. This is also consistent with what revealed in Table 2, suggesting that the higher (lower) performance of IMERG6 (GSMaP7) in depicting CAR activities may be attributed to its higher (lower) performance in illustrating the diurnal variation of precipitation over Taiwan.

Table 3. Statistical values for the comparison between the CWB data and SPPs shown in Figure 8. The unit of RMSE is \%. The lowest value of Scorr and the highest value of RMSE are marked by *. The sample size is 392 grid points.

\begin{tabular}{ccccc}
\hline & TRMM7 & IMERG5 & IMERG6 & GSMaP7 \\
\hline Scorr for Figure 8a & 0.78 & 0.82 & 0.84 & $0.54^{*}$ \\
RMSE for Figure 8a & 12.08 & 8.82 & 8.48 & $21.08^{*}$ \\
Scorr for Figure 8b & 0.74 & 0.79 & 0.83 & $0.69^{*}$ \\
RMSE for Figure 8b & 8.28 & 7.67 & 6.92 & $12.67^{*}$ \\
\hline
\end{tabular}

Additionally, we examine the performance of TRMM7 and IMERG6 in depicting the interannual variation of CAR activities area-averaged over Taiwan during the summers of 2000-2017. Figure 9a shows that both TRMM7 and IMERG6 are capable of depicting the interannual variation of contribution of CAR events to the total precipitation amount, similar to those seen in the CWB data. The Tcorr between the time series of TRMM7 (IMERG6) and the CWB data in Figure 9a is approximately 0.73 (0.80), which passes the $99 \%$ significant test.

(a) CAR prec. amount/Total events

(c) CAR prec. intensity/Total events
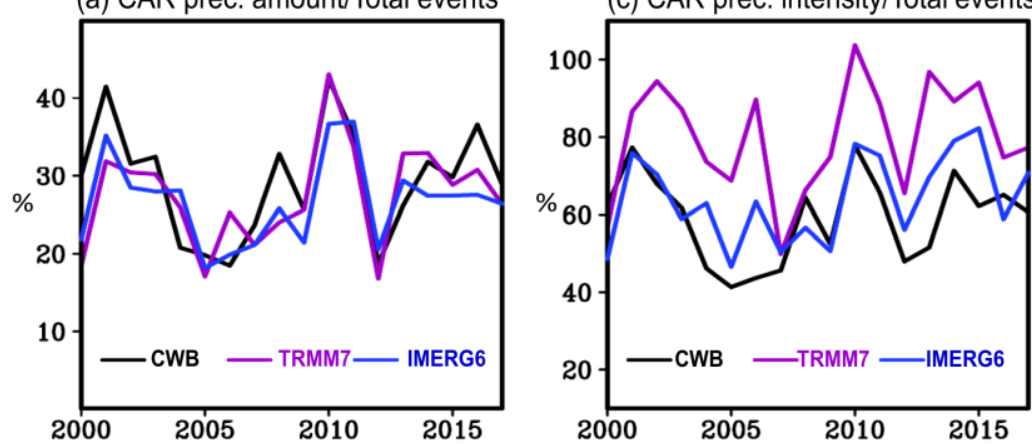

(b) CAR prec. days/Total events

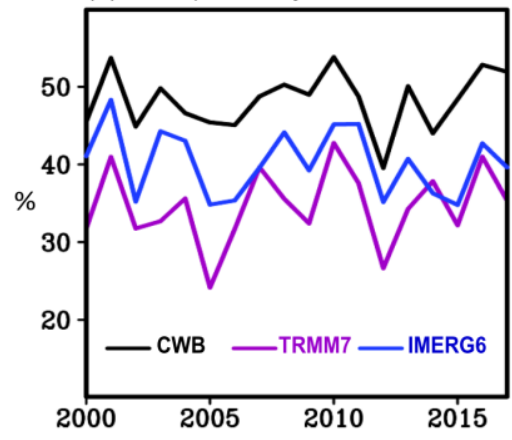

(d) Tcorr and RMSE for (a)-(c)

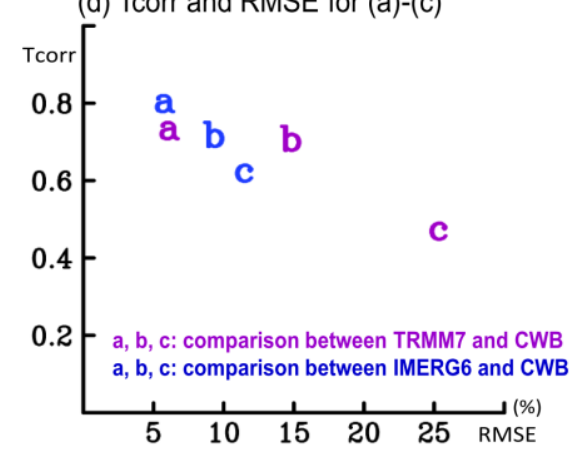

Figure 9. (a) The contribution of CAR events to the total precipitation amount that fell during the summers of 2000-2017. (b) The contribution of CAR days to total rainy days. (c) The contribution of CAR intensity (i.e., mean rain rate; unit: $\mathrm{mm}$ per event) to the intensity of total rainy events. In (a-c), contribution $=\frac{\text { CAR events }}{\text { Total precipitation events }} \times 100 \%$. In (d), the comparison of Tcorr and RMSE between time series in $(\mathbf{a}-\mathbf{c})$ is given, using the CWB data as the reference base, and denoted a-b-c, respectively. In (d), the purple color and blue color represents results related to TRMM7 and IMERG6, respectively. 
By separating the precipitation amount into the occurrence frequency and the intensity (i.e., precipitation amount $=$ occurrence frequency $\times$ intensity), it is however noted from Figure $9 \mathrm{~b}$ that both IMERG6 and TRMM7 tend to underestimate the contribution of CAR events to the occurrence frequency of total precipitation events, as compared to the CWB data. This might be because the SPPs, which utilize precipitation estimation from infrared and passive microwave sensors, are poor at retrieving local precipitation events over complex mountainous areas [42,48].

In contrast to Figure 9b, it can be noted in Figure 9c that both IMERG6 and TRMM7 tend to overestimate the contribution of CAR events to the intensity of total precipitation events. This might be because that satellite methods assume heavy precipitation results from deep clouds [42], and CAR events in Taiwan are belong to local deep convections [30]. Despite the bias seen in Figure 9b,c, we note from Figure 9d that IMERG6 (with higher Tcorr and lower RMSE) outperforms TRMM7 overall in illustrating the interannual variations of CAR activities. Therefore, we suggest that using IMERG6 to replace TRMM7 can benefit the researcher by obtaining more accurate characteristics of CAR in Taiwan.

\section{Discussions}

It was noted in Figure 1a that more (less) differences are observed between GSMaP7 (IMERG5 and IMERG6) and TRMM7 concerning the distribution of maximum precipitation over Taiwan. This might be because the land precipitation in GSMaP7 is adjusted using the CPC gauge-based analysis daily precipitation, while the land precipitation in TRMM7 and the IMERG products are adjusted using the GPCC gauge-based monthly precipitation $[1,3,4]$. In fact, by comparing the difference between the mean status of GSMaP7 (IMERG5 and IMERG6) and TRMM7 over a larger domain averaged during the summers of 2014-2017, we note that the difference between GSMaP7 and TRMM is also larger over Indochina (see Figure 10). In contrast, over the ocean areas of the Asian domain, larger differences can be found between IMERG5 and TRMM7.

(a) TRMM7

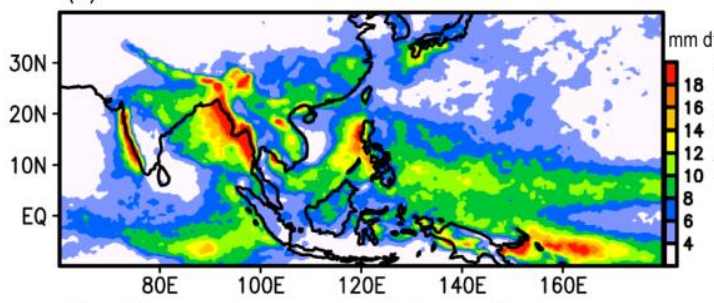

(b) Difference between IMERG5 and TRMM7

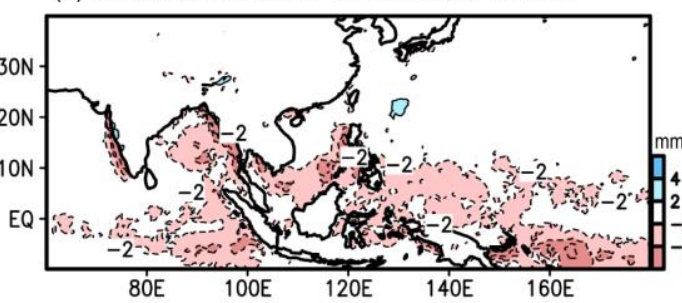

(c) Difference between IMERG6 and TRMM7

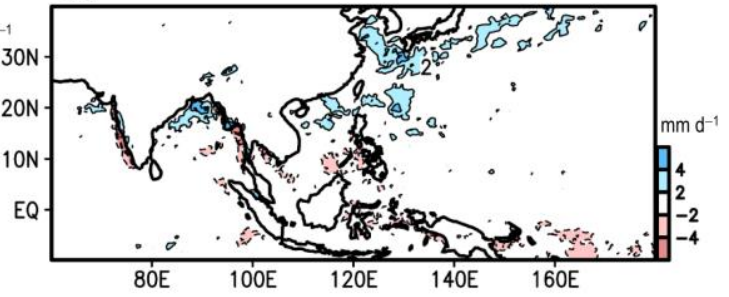

(d) Difference between GSMaP7 and TRMM7

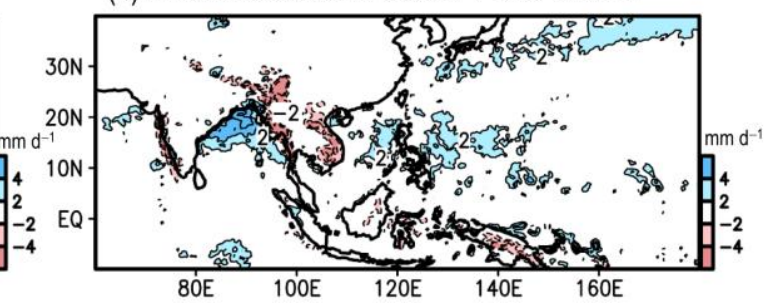

Figure 10. (a) Mean seasonal precipitation averaged during the summers of 2014-2017, estimated by TRMM7, over the Asian domain $\left(60^{\circ} \mathrm{E}-180^{\circ}, 10^{\circ} \mathrm{S}-40^{\circ} \mathrm{N}\right)$. (b) is related to (a), except for the difference between IMERG5 and TRMM7. (c) is similar to (b), except for the difference between IMERG6 and TRMM7. (d) is similar to (b), except for the difference between GSMaP7 and TRMM7.

Consistent with Figure 10, IMERG5 also has the daily variations in oceanic precipitation area-averaged over the Asian domain, more different to TRMM7 (Figure 11b; 5 day running mean applied). In contrast, for the daily variations in land-averaged precipitation, GSMaP7 appears to differ the most from TRMM7 (Figure 11a; 5 day running mean applied). To support the above arguments, we further calculate Tcorr and RMSE based on the time series given in Figure 11a,b and show the results in Figure 11c. It is confirmed that: (1) GSMaP7 has a more clear difference to TRMM7 (i.e., smaller 
Tcorr and larger RMSE) over the land; and (2) IMERG5 has a more clear difference to TRMM7 over the ocean. This information is particularly important for studies that tend to use GPM products to replace TRMM7 for estimating the moisture budget over the Asian domain [49-52].

(a) Asia land precip.; 5-day running avg.

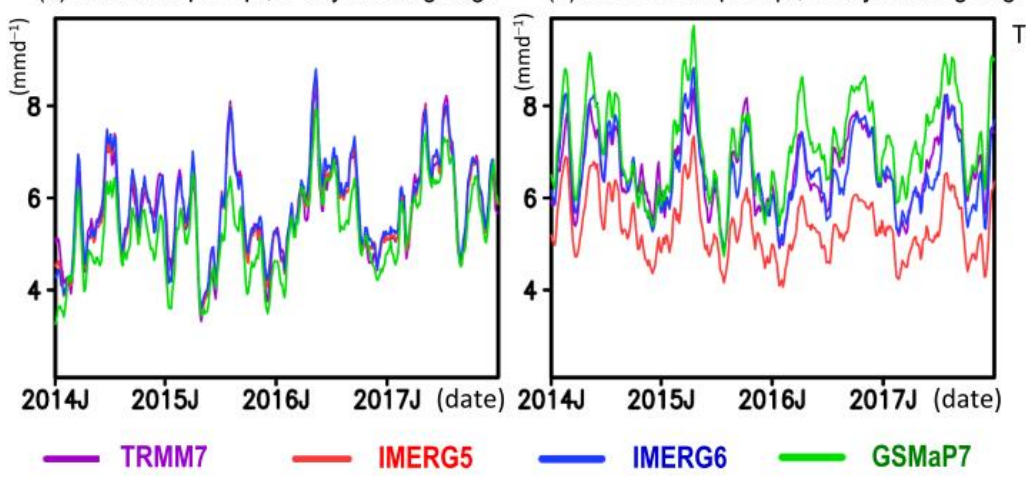

(c) Tcorr and RMSE for (a),(b)

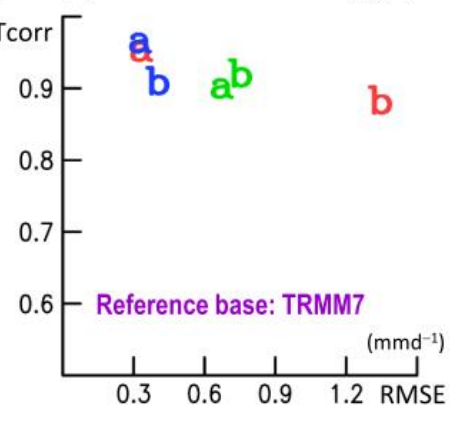

Figure 11. Time series of 5-day running averaged precipitation area-averaged over (a) the land and (b) the ocean of the Asian domain $\left(60^{\circ} \mathrm{E}-180^{\circ}, 10^{\circ} \mathrm{S}-40^{\circ} \mathrm{N}\right)$. The time series covered is from 2014 to 2017 JJAs (i.e., 368 days). (c) is based on (a,b), except for the calculation of Tcorr and RMSE between TRMM7 and the selected SPPs, including IMERG5 (red), IMERG6 (blue), and GSMaP7 (green).

\section{Conclusions}

This study evaluated the performance of multiple SPPs (including TRMM7, IMERG5, IMERG6, and GSMaP7) in depicting the variations of summer precipitation over Taiwan. The evaluations were performed at mean status, daily, interannual, and diurnal timescales. The major goal was to clarify whether IMERG6 is the best choice to replace TRMM7 for studying the summer precipitation variations over Taiwan. In addition, capabilities to apply SPPs in studying the most frequently observed weather pattern in Taiwan, that is, CAR event, is also examined. The performances of SPPs were evaluated using more than 400 gauges (i.e., CWB data) in Taiwan as the reference base for comparison.

Our analyses show that IMERG6 overall outperforms the other SPPs for depicting the spatial-temporal characteristics of summer precipitation over Taiwan varied at multiple timescales. Among the four SPPs, IMERG6 also has the smallest bias in depicting the characteristics of CAR activities in Taiwan. All the above findings suggest that more accurate results can be obtained if IMERG6 is used to replace TRMM7 for studying issues that are related to the summer precipitation in Taiwan. It is noted that above statement is true for the time period between 2000 and 2017. Further studies are suggested to evaluate the performance of multiple SPPs in Taiwan during the dry seasons.

Additionally, when investigating the differences between TRMM7 and the other SPPs over the Asian domain, we note that IMERG5 (GSMaP7) has the largest difference to TRMM7 over the ocean (land). This finding provides useful information for future studies that tend to use GPM products to replace TRMM7 for estimating the moisture budget over the Asian domain e.g., [49-52].

Author Contributions: Conceptualization, W.-R.H.; Data curation, W.-R.H., P.-Y.L. and Y.-H.C., Investigation, W.-R.H.; Software, P.-Y.L. and Y.-H.C.; Writing-original draft, W.-R.H.; Writing-review \& editing, W.-R.H., P.-Y.L., Y.-H.C. and C.-Y.L. All authors have read and agreed to the published version of the manuscript.

Funding: This research was funded by the Ministry of Science and Technology of Taiwan under MOST 106-2628-M-003-001-MY4 and MOST 108-2625-M-003-004. CYL was supported by MOST 107-2111-M-008-034 and MOST 108-2625-M-008-015.

Acknowledgments: We thank the provider of TRMM, IMERG, GSMaP, and CWB data.

Conflicts of Interest: The authors declare no conflict of interest. 


\section{References}

1. Huffman, G.J.; Bolvin, D.T.; Neklin, E.J.; Wolff, D.B.; Adler, R.F.; Gu, G.J.; Hong, Y.; Bowman, K.P.; Stocker, E.F. The TRMM Multisatellite Precipitation Analysis (TMPA): Quasi-global, multiyear, combined-sensor precipitation estimates at fine scales. J. Hydrometeorol. 2007, 8, 38-55. [CrossRef]

2. Hou, A.Y.; Kakar, R.K.; Neeck, S.; Azarbarzin, A.A.; Kummerow, C.D.; Kojima, M.; Oki, R.; Nakamura, K.; Iguchi, T. The Global Precipitation Measurement Mission. Bull. Am. Meteor. Soc. 2014, 95, 701-722. [CrossRef]

3. Huffman, G.J.; Bolvin, D.T.; Nelkin, E.J.; Stocker, E.F.; Tan, J. V06 IMERG Release Notes; NASA/GSFC: Greenbelt, MD, USA, 2019.

4. Mega, T.; Ushio, T.; Takahiro, M.; Kubota, T.; Kachi, M.; Oki, R. Gauge-Adjusted Global Satellite Mapping of Precipitation. IEEE Trans. Geosci. Remote Sens. 2019, 57, 1928-1935. [CrossRef]

5. Tian, Y.; Peters-Lidard, C.D.; Choudhury, B.J.; Garcia, M. Multitemporal Analysis of TRMM-Based Satellite Precipitation Products for Land Data Assimilation Applications. J. Hydrometeorol. 2007, 8, 1165-1183. [CrossRef]

6. Libertino, A.; Sharma, A.; Lakshmi, V.; Claps, P. A global assessment of the timing of extreme rainfall from TRMM and GPM for improving hydrologic design. Environ. Res. Lett. 2016, 11, 5. [CrossRef]

7. Sungmin, O.; Foelsche, U.; Kirchengast, G.; Fuchsberger, J.; Tan, J.; Petersen, W.A. Evaluation of GPM IMERG Early, Late, and Final rainfall estimates using WegenerNet gauge data in southeastern Austria. Hydrol. Earth Syst. Sci. 2017, 21, 6559-6572. [CrossRef]

8. Lu, D.; Yong, B. Evaluation and Hydrological Utility of the Latest GPM IMERG V5 and GSMaP V7 Precipitation Products over the Tibetan Plateau. Remote Sens. 2018, 10, 2022. [CrossRef]

9. Wang, C.; Tang, G.; Han, Z.; Guo, X.; Hong, Y. Global intercomparison and regional evaluation of GPM IMERG Version-03, Version-04 and its latest Version-05 precipitation products: Similarity, difference and improvements. J. Hydrol. 2018, 564, 342-356. [CrossRef]

10. Lu, X.Y.; Tang, G.Q.; Wang, X.Q.; Liu, Y.; Ji, L.H.; Xie, G.H.; Li, S.; Zhang, Y.X. Correcting GPM IMERG precipitation data over the Tianshan Mountains in China. J. Hydrol. 2019, 575, 1239-1252. [CrossRef]

11. Mazzoglio, P.; Laio, F.; Balbo, S.; Boccardo, P.; Disabato, F. Improving an Extreme Rainfall Detection System with GPM IMERG data. Remote Sens. 2019, 11, 677. [CrossRef]

12. Salles, L.; Frédéric, S.; Roig, H.; Almeida, T.; Olivetti, D.; Ferreira, W. Seasonal effect on spatial and temporal consistency of the new GPM-based IMERG-v5 and GSMaP-v7 satellite precipitation estimates in Brazil's central plateau region. Water 2019, 11, 668. [CrossRef]

13. Prakash, S.; Mitra, A.K.; Pai, D.S.; AghaKouchak, A. From TRMM to GPM: How well can heavy rainfall be detected from space? Adv. Water Resour. 2016, 88, 1-7. [CrossRef]

14. Tan, M.L.; Duan, Z. Assessment of GPM and TRMM Precipitation Products over Singapore. Remote Sens. 2017, 9, 720. [CrossRef]

15. Derin, Y.; Anagnostou, E.; Berne, A.; Borga, M.; Boudevillain, B.; Buytaert, W.; Chang, C.-H.; Chen, H.; Delrieu, G.; Hsu, Y.C.; et al. Evaluation of GPM-era Global Satellite Precipitation Products over Multiple Complex Terrain Regions. Remote Sens. 2019, 11, 2936. [CrossRef]

16. Sahlu, D.; Nikolopoulos, E.I.; Moges, S.A.; Anagnostou, E.N.; Hailu, D. First evaluation of the day-1 IMERG over the upper Blue Nile Basin. J. Hydrometeorol. 2016, 17, 2875-2882. [CrossRef]

17. Tang, G.; Zeng, Z.; Long, D.; Guo, X.; Yong, B.; Zhang, W.; Hong, Y. Statistical and Hydrological Comparisons between TRMM and GPM Level-3 Products over a Midlatitude Basin: Is Day-1 IMERG a Good Successor for TMPA 3B42V7? J. Hydrometeorol. 2016, 17, 121-137. [CrossRef]

18. Tan, M.L.; Santo, H. Comparison of GPM IMERG, TMPA 3B42 and PERSIANN-CDR satellite precipitation products over Malaysia. Atmos. Res. 2017, 202, 63-76. [CrossRef]

19. Xu, R.; Tian, F.; Yang, L.; Hu, H.; Lu, H.; Hou, A. Ground validation of GPM IMERG and TRMM 3B42V7 rainfall products over southern Tibetan Plateau based on a high-density rain-gauge network. J. Geophys. Res. Atmos. 2017, 122, 910-924. [CrossRef]

20. Jiang, S.; Ren, L.; Xu, C.Y.; Yong, B.; Yuan, F.; Liu, Y.; Yang, X.; Zeng, X. Statistical and hydrological evaluation of the latest Integrated Multi-satellitE Retrievals for GPM (IMERG) over a midlatitude humid basin in South China. Atmos. Res. 2018, 214, 418-429. [CrossRef] 
21. Jiang, L.G.; Bauer-Gottwein, P. How do GPM IMERG precipitation estimates perform as hydrological model forcing? Evaluation for 300 catchments across Mainland China. J. Hydrol. 2019, 572, 486-500. [CrossRef]

22. Wu, Y.; Zhang, Z.; Huang, Y.; Jin, Q.; Chen, X.; Chang, J. Evaluation of the GPM IMERG v5 and TRMM $3 B 42$ v7 Precipitation Products in the Yangtze River Basin, China. Water. 2019, 10, 1459. [CrossRef]

23. Chen, S.Y.; Huang, W.R. Evaluation on the performance of TRMM, CMORPH, and PERSIANN in depicting the diurnal precipitation variation in Taiwan. Atmos. Sci. 2017, 45, 167-191. (In Chinese)

24. Huang, W.R.; Chang, Y.H.; Liu, P.Y. Assessment of IMERG precipitation over Taiwan at multiple timescales. Atmos. Res. 2018, 214, 239-249. [CrossRef]

25. Kishtawal, C.M.; Krishnamurti, T.N. Diurnal variation of summer rainfall over Taiwan and its detection using TRMM observations. J. Appl. Meteor. Climatol. 2001, 40, 331-344. [CrossRef]

26. Yeh, N.C.; Chuang, Y.C.; Peng, H.S.; Hsu, K.L. Bias Adjustment of Satellite Precipitation Estimation Using Ground-Based Observation: Mei-Yu Front Case Studies in Taiwan. Asia-Pac. J. Atmos. Sci. 2019. [CrossRef]

27. Gelaro, R.; McCarty, W.; Suárez, M.J.; Todling, R.; Molod, A.; Takacs, L.; Randles, C.A.; Darmenov, A.; Bosilovich, M.G.; Reichle, R.; et al. The Modern-Era Retrospective Analysis for Research and Applications, Version 2 (MERRA-2). J. Clim. 2017, 30, 5419-5454. [CrossRef]

28. Tan, J.; Huffman, G.J. Computing Morphing Vectors for Version 06 IMERG; NASA/GSFC: Greenbelt, MD, USA, 2019.

29. Ushio, T.; Sasashige, K.; Kubota, T.; Shige, S.; Okamoto, K.; Aonashi, K.; Inoue, T.; Takahashi, N.; Iguchi, T.; Kachi, M.; et al. A Kalman filter approach to the Global Satellite Mapping of Precipitation (GSMaP) from combined passive microwave and infrared radiometric data. J. Meteorol. Soc. Jpn. 2009, 87A, 137-151. [CrossRef]

30. Huang, W.R.; Chang, Y.H.; Cheng, C.T.; Hsu, H.H.; Tu, C.Y.; Kitoh, A. Summer Convective Afternoon Rainfall Simulation and Projection using WRF Driven by Global Climate Model. Part I: Over Taiwan. Terr. Atmos. Ocean. 2016, 27, 659-671. [CrossRef]

31. Cressman, G.P. An operational objective analysis system. Mon. Weather Rev. 1959, 87, 367-374. [CrossRef]

32. Hong, J.S.; Cao, J.H. Objective analysis of the rain gauge observations by using the Cressman analysis method. Atmos. Sci. 2011, 39, 201-213. (In Chinese)

33. Huffman, G.J.; Bolvin, D.T.; Braithwaite, D.; Hsu, K.; Joyce, R.; Kidd, C.; Nelkin, E.J.; Sorooshian, S.; Tan, J.; Xie, P. Algorithm Theoretical Basis Document (ATBD) Version 5.1: NASA Global Precipitation Measurement (GPM) Integrated Multi-SatellitE Retrievals for GPM (IMERG); NASA/GSFC: Greenbelt, MD, USA, 2017.

34. Kubota, T.; Shige, S.; Hashizume, H.; Ushio, T.; Aonashi, K.; Kachi, M.; Okamoto, K. Global precipitation map using satellite-borne microwave radiometers by the GSMaP Project: Production and validation. IEEE Trans. Geosci. Remote Sens. 2007, 45, 2259-2275. [CrossRef]

35. Wilks, D.S. Statistical Methods in the Atmospheric Sciences, 1st ed.; Academic Press: Cambridge, MA, USA, 1995; p. 467.

36. Wang, C. On the Calculation and Correction of Equitable Threat Score for Model Quantitative Precipitation Forecasts for Small Verification Areas: The Example of Taiwan. Weather Forecast. 2014, 29, 788-798. [CrossRef]

37. Wang, C.; Kung, C.; Lee, C.; Chen, T.J. Development and Evaluation of Mei-Yu Season Quantitative Precipitation Forecasts in Taiwan River Basins Based on a Conceptual Climatology Model. Weather Forecast. 2012, 27, 586-607. [CrossRef]

38. Wang, C.; Huang, S.; Chen, S.; Chang, C.; Tsuboki, K. Cloud-Resolving Typhoon Rainfall Ensemble Forecasts for Taiwan with Large Domain and Extended Range through Time-Lagged Approach. Weather Forecast. 2016, 31, 151-172. [CrossRef]

39. Yang, T.H.; Yang, S.C.; Ho, J.Y.; Lin, G.F.; Hwang, G.D.; Lee, C.S. Flash flood warnings using the ensemble precipitation forecasting technique: A case study on forecasting floods in Taiwan caused by typhoons. J. Hydrol. 2015, 520, 367-378. [CrossRef]

40. Levizzani, V.; Bauer, P.; Turk, F.J. Measuring Precipitation from Space: EURAINSAT and the Future; Springer Netherlands: Heidelberg, Germany, 2007; p. 724.

41. Hannachi, A.; Jolliffe, I.; Stephenson, D. Empirical orthogonal functions and related techniques in atmospheric science: A review. Int. J. Climatol. 2007, 27, 1119-1152. [CrossRef]

42. Shige, S.; Kida, S.; Ashiwake, H.; Kubota, T.; Aonashi, K. Improvement of TMI rain retrievals in mountainous areas. J. Appl. Meteor. Climatol. 2013, 52, 242-254. [CrossRef] 
43. Sun, Q.; Miao, C.; Duan, Q.; Ashouri, H.; Sorooshian, S.; Hsu, K.L. A review of global precipitation data sets: Data sources, estimation, and intercomparisons. Rev. Geophys. 2018, 56, 79-107. [CrossRef]

44. Teo, C.-K.; Koh, T.-Y.; Lo, J.; Bhatt, B. Principal Component Analysis of Observed and Modeled Diurnal Rainfall in the Maritime Continent. J. Clim. 2011, 24, 4662-4675. [CrossRef]

45. Huang, W.R.; Wang, S.S.-Y. Future changes in propagating and non-propagating diurnal rainfall over East Asia. Clim. Dyn. 2017, 49, 375-389. [CrossRef]

46. Huang, W.R.; Chang, Y.H. Characteristics and mechanisms of the diurnal variation of winter precipitation in Taiwan. Int. J. Climatol. 2018, 38, 3058-3068. [CrossRef]

47. Tan, J.; Huffman, G.J.; Bolvin, D.T.; Nelkin, E.J. Diurnal Cycle of IMERG V06 Precipitation. Geophys. Res. Lett. 2019, 46, 13584-13592. [CrossRef]

48. Derin, Y.; Yilmaz, K.K. Evaluation of Multiple Satellite-Based Precipitation Products over Complex Topography. J. Hydrometeor. 2014, 15, 1498-1516. [CrossRef]

49. Wang, Z.; Duan, A.; Yang, S.; Ullah, K. Atmospheric moisture budget and its regulation on the variability of summer precipitation over the Tibetan Plateau. J. Geophys. Res. Atmos. 2016, 122, 614-630. [CrossRef]

50. Chen, J.; Bordoni, S. Intermodel spread of East Asian summer monsoon simulations in CMIP5. Geophys. Res. Lett. 2014, 41, 1314-1321. [CrossRef]

51. Prasanna, V.; Annamalai, H. Moist dynamics of extended monsoon breaks over South Asia. J. Clim. 2012, 25, 3810-3831. [CrossRef]

52. Unnikrishnan, C.K.; Rajeevan, M. Atmospheric water budget over the South Asian summer monsoon region. Meteorol. Atmos. Phys. 2018, 130, 175-190. [CrossRef]

(C) 2020 by the authors. Licensee MDPI, Basel, Switzerland. This article is an open access article distributed under the terms and conditions of the Creative Commons Attribution (CC BY) license (http://creativecommons.org/licenses/by/4.0/). 